\title{
9 The role of seed systems development in African agricultural transformation
}

\author{
Joseph D. DeVries
}

\section{Introduction}

Subsistence-level farming in Africa is unsustainable. As rural populations grow and spread, agricultural lands and other resources are steadily depleted and rendered incapable of providing a stable, decent existence. Poverty, hunger and malnutrition become the dominant themes in rural communities, and people lose faith in farming as a livelihood. Climate change, with its attendant droughts, floods and other extreme weather events, exacerbates this trend. The result is high rates of rural-urban migration, leading to an overflow of nonproductive people living in Africa's cities. Many, especially the youth, make desperate attempts to migrate to Europe and other developed regions. Others turn to radical religious and political factions which threaten the stability of whole regions of the continent and other parts of the world.

For decades, this has been the dominant trend across much of rural Africa. For lack of better options, smallholder farmers have continued to depend on the same, subsistence-style farming practices as generations of farmers before them. Grain crop yields in many countries have fluctuated around approximately $1 \mathrm{MT} / \mathrm{ha}$, and rural economies, with a few exceptions, have stagnated. Meanwhile, population growth rates averaging $2.7 \%$ drive a steady increase in demand for food, education and health services which weak economies simply cannot supply. Much of the fallout from failing agricultural systems is absorbed by women, who care for children and also supply a large portion of the labour on Africa's farms (Palacios-Lopez et al., 2015).

\section{A straightforward solution}

There is a solution to the trap of subsistence agriculture. Throughout history and around the world, sustained increases in agricultural productivity and rural economic growth have been catalyzed by the introduction of seed of improved, locally adapted crop varieties which make more efficient use of sunlight, water and soil nutrients, resist pests and diseases and mature more quickly. Broad experience throughout the world - and now, in Africa as well - has shown that few other attempts to increase farmers' yields have proven as successful or as sustainable. 
In recent years, the decades-long trend of static or declining crop yields in Africa has been reversed in several countries following the broad introduction and promotion of seed of improved, adapted crop varieties. In the past 13 years, yield increases in Africa have outstripped the progress of the previous 40 years. Food production on a per capita basis has likewise increased by $12 \%$ since 2000 (The Bill and Melinda Gates Foundation, 2018, unpublished). The biggest gains have been made in East Africa, where per capita cereal production has risen 50\% since 2000. Not surprisingly, East Africa is also where the adoption of improved seed, especially hybrid maize seed, has flourished (The Economist, 2016).

Southern Africa, too, has benefited significantly from modern crop breeding and seed supply, especially in South Africa and Zimbabwe, and increasingly in Zambia and Malawi as well. However, the farmers of a number of countries in Southern Africa are yet to gain access to higher-yielding seed, with the situations in Angola, Botswana, the Democratic Republic of Congo and Madagascar being of particular concern. As all of these are maize-producing countries, one relatively quick solution is likely to be the introduction and promotion of higher-yielding maize varieties, including hybrids.

From 2007 to 2017, average maize yields in Uganda increased by 70\%, from less than 1.5 MT/ha to 2.5 MT/ha. Meanwhile, Uganda's maize harvest increased from 1.26 million metric tons (MT) to over 3 million MT, an increase of $138 \%$. Over this same period, Ethiopia's average maize yields nearly doubled, from less than $2 \mathrm{MT}$ /ha to $3.7 \mathrm{MT} /$ ha (Figure 9.1). Ethiopia's maize harvest grew 143\%.

The dramatic gains in maize productivity in Uganda and Ethiopia were achieved during a period of rapid increases in the supply and adoption of improved seed. Data collected from companies during this period show supply increasing from 8.3 MT per year to 26,700 MT per year in Uganda (not shown) and from $260 \mathrm{MT}$ per year to 57,350 MT per year in Ethiopia. This data, however, does not capture the actual baselines for seed supply in either country.

Thanks to recent investments in the breeding of African crops by the Bill and Melinda Gates Foundation, USAID, The Rockefeller Foundation and several

\section{Production Data for Maize in Ethiopia}

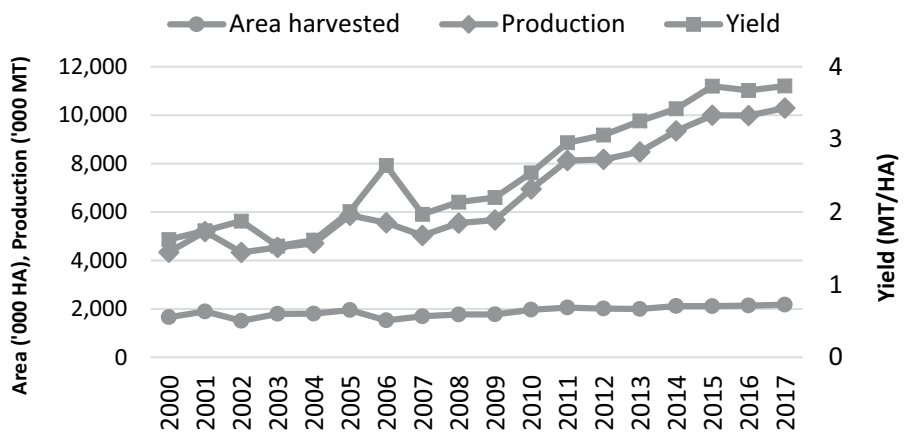

Figure 9.1 Maize production data for Ethiopia, 2000-2017

Source: FAOSTAT, 2019 


\section{Seed Supply by AGRA-Affiliated Seed Companies in Ethiopia, 2007-2017}

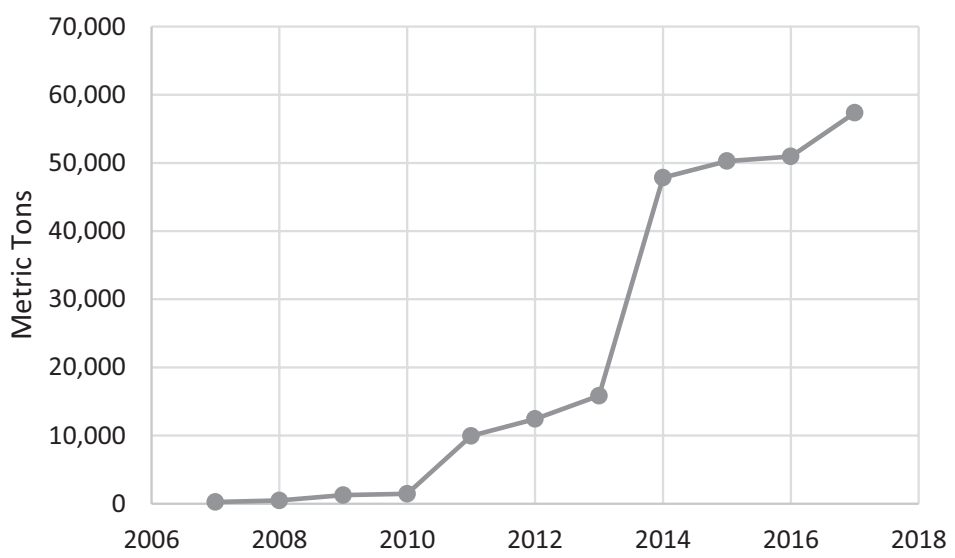

Figure 9.2 Improved seed supply in Uganda and Ethiopia, 2007-2017

Source: AGRA/PASS Database, 2018

other international donor agencies, improved varieties have now been bred for most of Africa's staple crops, which are higher-yielding, drought-tolerant, disease-resistant and earlier-maturing. A recent publication has identified 650 varieties of 14 staple food crops which have been officially released in the past 10 years (AGRA, 2018).

Currently, AGRA, the CGIAR and several other national and international development agencies are receiving financial support to establish seed delivery systems based on investments in private seed companies, agro-dealers, seed awareness building (extension) and better seed policies. The evidence from official data and from observations of farmers' fields is that it is working (Figure 9.2). However, these efforts are concentrated in approximately 12 countries, leaving farmers in many other African countries with major agricultural potential without access to the new crop varieties or delivery systems which could allow them to intensify their crop production and increase yields.

\section{Why is seed so critical?}

Crops grown using seed of varieties developed through modern breeding mature quicker, resist pests and diseases, are more drought tolerant and partition a greater portion of their biomass into the harvested portion of the crop. Simply by substituting seed of a genetically improved variety for a traditional variety, farmers can increase their crop yields by 20 to $30 \%$. But the changes don't end there. As farmers observe the greater vigour of the new crop, they begin to apply more manure, buy more fertilizer and improve their overall crop management 
practices, including planting in rows and weeding the crop more regularly. Thus, the combined effects of seed of new varieties, greater nutrient supply and improved crop management allow farmers to double, triple or even quadruple their yields.

Around the world the introduction and adoption of seed of improved varieties has been central to this challenge. Hybrid maize seed transformed the American Midwest in the 1930s and 40s. Improved, "Green Revolution" wheat varieties bred by Norman Borlaug transformed Mexico and then the Indian subcontinent in the 1950s and 60s. Modern rice breeding and seed supply led to the transformation of the rice crop - and eventually, the economies - of Southeast Asia in the 1970s and 80s (Pingali, 2012). As climate change accelerates bringing more frequent and more intense periods of crop moisture stress, the greater resource-use-efficiency of modern crop genetic improvement has become essential to increasing farmer productivity and the resilience of crop production systems worldwide, especially in Africa (Webber et al., 2018).

\section{Africa's emerging green revolution}

Africa's green revolution, in contrast, was delayed by several factors. First, the far greater diversity of Africa's agro-ecologies, food crops and production systems created a longer lag phase during which new varieties were still being bred. Second, the existence of many relatively small countries in SSA has tended to reduce the flow of successful technologies across large areas. Third, whereas the key technologies that drove green revolutions in Latin America and Asia were delivered to farmers through large, publicly managed distribution schemes, supply in Africa has been largely driven by private sector, which historically suffered from less access to capital and skilled human resources. Finally, Africa's governments lacked appropriate seed policies and other measures to enable the private sector to operate freely and take seed to farmers.

In the early years of the 21st century, a small team of programme officers at The Rockefeller Foundation began combining investments in agro-ecologybased crop breeding with support to private, local seed companies and villagebased agro-dealers as a means of providing smallholder farmers with regular, dependable access to seed of improved, locally adapted crop varieties (DeVries and Toenniessen, 2002). Local crop yields increased, fueling greater demand for seed and the growth of national seed and fertilizer businesses. The Rockefeller Foundation model for seed systems development led to the establishment in 2006 of the Programme for Africa's Seeds (PASS), which spearheaded the development of seed supply in 13 countries across West, East and Southern Africa.

Over this period, nearly 700 improved crop varieties developed by national agricultural research systems (NARS) and Consultative Group on International Agricultural Research (CGIAR) breeders have been approved by Africa's seed regulatory agencies, and over 100 private, independent seed companies have been established to multiply, package and sell seed to smallholder farmers. By 2016, annual seed production and sales from these companies had risen to 127,000 MT (AGRA, 2017), sufficient to plant an estimated 7 million hectares. 
Hence, the food security scenario in the 13 countries targeted for seed systems development is broadly hopeful (Sanchez, 2015).

However, numerous African countries remain where seed supply can catalyze higher yields, reduce food shortages and jump-start rural economies, but only where the model described previously is yet to be introduced. These include 16 key agrarian countries with a total population of over 300 million people and an estimated 38 million farm families. The average level of chronic child malnutrition (stunting) in these countries is $38 \%$.

For the vast majority of the farmers in these countries, the only sustainable means of improving their living conditions is through increased agricultural productivity. However, due to national boundaries and a lack of investment in seed systems development at a national level, tens of millions of farmers in these "left-behind" countries remain trapped behind a "low-yield seed barrier". As a result, crop yields in these countries have largely stagnated, whereas crop yields in countries where seed systems have been actively developed have increased significantly, as illustrated in the chart that follows (Figure 9.3).

\section{A model for yield increases proven in Africa}

Public-private seed systems are modular in structure, consisting of four main, interconnected parts: crop improvement, seed enterprise development, private sector-led extension and agro-dealer development (Figure 9.4).

These can be briefly described as follows.

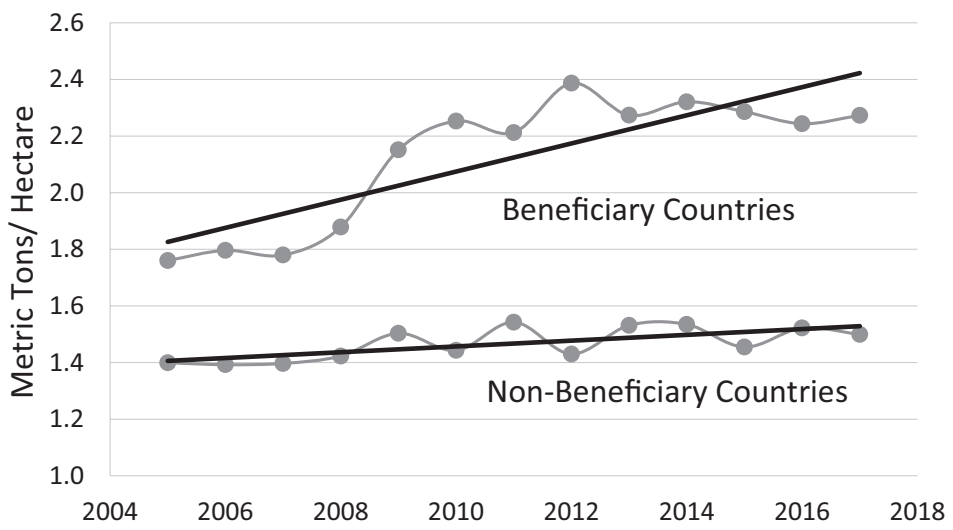

Figure 9.3 Maize and rice crop yield trends in countries benefiting from seed systems assistance vs. those nonbeneficiary countries, 2005-2017

Note: Trendlines for PASS countries including Burkina Faso, Ethiopia, Ghana, Kenya, Malawi, Mali, Mozambique, Niger, Nigeria, Rwanda, Senegal, Sierra Leone, Tanzania, Uganda and Zambia; proposed countries include Angola, Benin, Botswana, Burundi, Chad, Cote d'Ivoire, Democratic Republic of Congo, Eritrea, Guinea, Madagascar and Togo.

Source: FAOSTAT, 2019 
Aim: Mobilizing New Seed

Scaling Up Seed Production

Farmer Adoption at Scale

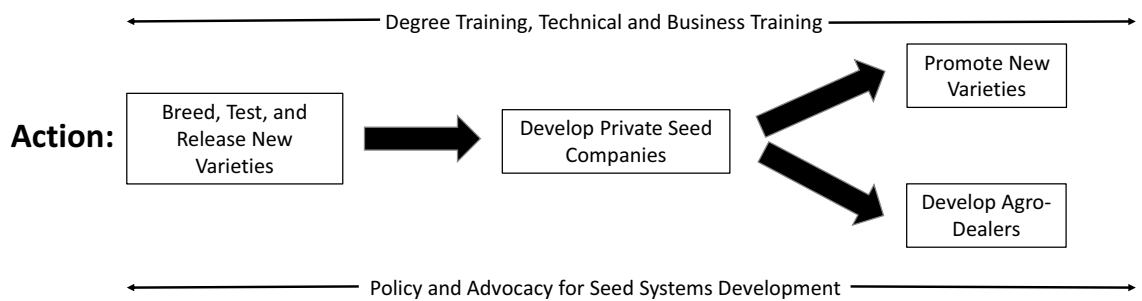

Figure 9.4 Seed systems development schematic, showing main points of entry and their functions

\section{Breeding and release of new varieties}

The journey towards adoption of high-yielding crop varieties among smallholder farmers begins with training and supporting a cadre of crop scientists to engage in the introduction, testing and selection of improved varieties of the countries' main food crops. This work is performed by scientists and technicians working in national agricultural research institutes. The large number of new, Africa-adapted crop varieties developed over the past decade represents an enormous advantage in developing the seed systems of countries heretofore left behind. Once released by the national agricultural research system, these varieties can be licensed to private, independent seed companies for commercialization. These licenses often include payment of royalties back to the institution, representing a new source of revenue for these often-neglected public entities.

\section{Seed enterprise development}

The identification and release of higher-yielding varieties needs to be paralleled by the establishment of a critical number private, independent seed companies which compete for sales of seed to farmers through an open market system. Experience has shown that entrepreneurs, including seed entrepreneurs, exist throughout Africa but often lack the specialized knowledge or capital to establish formal companies capable of producing, packaging and distributing improved seed. Women seed entrepreneurs have figured strongly in the emergence of the seed business in Africa.

Applying business principles to seed supply in countries historically dependent on government or NGO-led supply models is a positively disruptive intervention, which tends to attract attention and constructive debate at several levels of the society. Seed companies receive start-up capital and intensive training in business practices, which are specifically effective in reaching smallholder farmers (such as selling seed in small, 1 or $2 \mathrm{~kg}$ packages, marketing seed in open-air 
markets, placing demonstrations in areas frequented by farmers, broadcasting information in local languages via radio, etc.). Many of these seed companies grow rapidly and sustainably, eventually replacing the bulk of public and voluntary organizations' seed supply with a more professional, self-improving model. Competition between seed companies seeking to add to their market share leads to added innovations, such as seed treatments which protect the crop against fungal pathogens, nematodes and insects during early stages of growth.

\section{Private sector-led extension}

Improved seed can achieve little if farmers are unaware of its value. In parallel with the establishment of seed supply, extension activities focus on the demonstration and promotion of seed of new varieties at farmer level. Self-employed "Village-Based Advisors" (VBAs) are recruited, trained to teach farmers how to cultivate the new seed using fertilizer, row-spacing, weeding and other modern practices and facilitated to rapidly distribute hundreds of thousands of small (50 gram) packs of new seed plus small (200 gram) packs of fertilizer to fellow farmers who then engage in a mass experiential learning exercise by growing the new crop on small portions of their land. The better results obtained on these small plots is usually sufficient to convince most farmers to purchase a larger quantity of seed and fertilizer in the following season and provides a ready source of demand for the new seed companies and fertilizer suppliers.

The adoption and spread of mobile phones among farmers has dramatically increased the impact that can be achieved through private sector-led extension and VBAs, more specifically. VBA's can be facilitated to communicate a wide range of messages regarding seed performance, seed availability, farmer field day meetings, as well as opportunities for accessing fertilizer and other inputs, and even grain marketing opportunities.

\section{Agro-dealer development}

The final link in the seed value chain is village-level supply of seed through agro-dealers. This step involves providing start-up capital and technical assistance to village-based entrepreneurs to open their own seed and input supply shops (known widely as agro-dealers). The establishment of private, locally owned input shops ensures the steady supply of seed, fertilizer and other technology at a local level and removes, once and for all, the physical access barrier to these and other technologies. Agro-dealerships also offer new sources for women and youth employment in rural areas. Young, village-based entrepreneurs are often key to introducing new seed through these small businesses.

\section{The role of government}

It is important to point out that seed systems development cannot be achieved through voluntary and entrepreneurial action alone. In addition to 
action-oriented investments in seed supply, placing improved seed at the top of the agenda for agricultural development requires direct, consistent engagement with high-level government officials. The role of public, national agricultural research institutions and seed regulatory agencies is, of course, central to much of the activity described earlier.

As governments begin to recognize the value placed on seed (and fertilizer) among smallholder farmers, they often capitalize on the demand for improved seed by setting up subsidy schemes to encourage broad adoption. These schemes can have a positive or negative impact on seed markets, depending on how well they are administered but are ubiquitous wherever improved seed becomes a matter of importance to large numbers of farmers (Timmer, 1992). Key for farmers is preserving the element of choice in the seed they plant and timely delivery of the seed to local agro-dealers.

\section{The emergence of modernized grain markets}

Although grain traders are not usually an integral part of seed systems, they play a crucial role in shaping them. Their growth and development into modernized suppliers of tradable surpluses often parallels the development of seed systems. This happens in several ways. As farmers begin to produce reliable surpluses of grains as a result of the higher yields obtained from improved seed, grain traders are quick to see the new opportunities represented in cleaning, processing, packaging and exporting these surpluses. Modernized grain markets and standardized, packaged grain products, however, require consistency with regard to grain colour, texture, taste and quality. These requirements can only be met through supply of the corresponding seed. As a result, grain traders begin to pay close attention to seed supply, often supplying seed in advance to farmers in their production networks.

\section{The opportunity and the payoff}

Much of Africa's future hinges on how the continent as a whole deals with its lingering food and nutritional challenge. Recent experience with the adoption of seeds of modern, high-yielding varieties among farmers in a number of countries has proven that they are capable of producing much higher yields than previously believed possible. This has provided crucial evidence that a broader African Green Revolution is an achievable goal.

For Africa as a continent to develop normally and contribute to feeding the rest of the world, agricultural advances - especially higher-yielding, locally adapted seeds of the continent's major food crops - cannot be limited to a select handful of countries. They must be extended to all countries and to as many farmers as possible.

The experience and lessons learned over the past decade in 15 countries has produced a reliable model for seed systems development in Africa and significantly reduced the risks associated with extending this intervention to a new 
group of countries which are critical to peace, stability and food security on the continent. Indeed, the juxtaposition of the haves and have-nots with regard to improved seed in Africa has created a new sense of urgency around getting seed to the rest of Africa's farmers and begs the question, "If not now, then when, and if not us, then who?"

\section{References}

AGRA. (2017). Seeding an African Green Revolution. The Alliance for a Green Revolution in Africa. Nairobi, Kenya. Eds. J.D. DeVries, and Z. Masiga, p. 71

AGRA. (2018) Catalogue of Varieties from AGRA-Supported Breeding Programs. Eds. J.D. DeVries, L. Gichuru, J. Ininda, M. Muthama, P. Tongoona. Nairobi, Kenya: AGRA.143pp. Bill and Melinda Gates Foundation. (2018) Internal study based on data from FAOSTAT and UN Population Division, shared by Tom Kehoe.

DeVries, J.D. and G.H. Toenniessen (2002) Biotechnology, Breeding and Seed Systems for African Crops I. Book of Abstracts for 1st General Meeting of Collaborators of The Rockefeller Foundation held in Entebbe, Uganda, November 2-5.

The Economist. (2016) A Green Revolution: African Agriculture. The Economist, March 12, www.economist.com/briefing/2016/03/12/a-green-evolution

FAOSTAT. (2019). Data downloaded from online database of the United Nations Food and Agricultural Organization (http://www.fao.org/faostat/en/\#data/QC).

Palacios-Lopez, A., L. Christiaensen, and T. Kilic. (2015) How Much of the Labor in African Agriculture Is Provided by Women? World Bank Policy Research Working Paper No. 7282, World Bank Group, Washington, DC, http://documents.worldbank.org/curated/en/9796 71468189858347/pdf/WPS7282.pdf

Pingali, P.L. (2012). Green Revolution: Impacts, limits, and the path ahead. Proc Natl Acad Sci, 109(31):12302-8.

Sanchez, P. (2015). En route to plentiful food production in Africa. Nature Plants. January 8, 2015.

Timmer, C.P. (1992) Agriculture and the State: Growth, Employment, and Poverty in Developing Countries. Ed. C.P. Timmer. Ithaca, NY: Cornell University Press, 321p.

Webber,T.,A.Haensler,D.Rechid,S.Pfeifer,B.Eggert,and T.Jacob (2018) Analyzing Regional Climate Change in Africa in a $1.5,2$, and $3^{\circ} \mathrm{C}$ Global Warming World. Earth's Future, Vol. 6, Issue 4, pp. 643-655, https://agupubs.onlinelibrary.wiley.com/doi/full/10.1002/ $2017 \mathrm{EF} 000714$. 